\title{
Vibrational spectra of quercetin and their interpretation with quantum-mechanical density-functional method
}

\author{
${ }^{1}$ Kutovyy S., ${ }^{1}$ Savchuk R., ${ }^{1}$ Bashmakova N., ${ }^{1}$ Stanovyi O. and \\ ${ }^{2}$ Palchykivska L. \\ ${ }^{1}$ Faculty of Physics, Taras Shevchenko National University of Kyiv, 64/13 \\ Volodymyrska Street, 01601 Kyiv, Ukraine, sangulaire@gmail.com \\ ${ }^{2}$ Department of Molecular and Quantum Biophysics, Institute of Molecular Biology \\ and Genetics, National Academy of Sciences of Ukraine, 150 Academician \\ Zabolotnyi Street, 03143 Kyiv, Ukraine.
}

Received: 05.07 .2021

\begin{abstract}
Experimental vibrational (Raman and IR-absorption) spectra are obtained for microcrystalline powder of quercetin in the spectral range of $400-1800 \mathrm{~cm}^{-1}$ at the room temperature. Optimized geometries of two stable isomers of quercetin molecule are calculated with a density-functional method at the level CAM B3LYP/6-311++G(d,p). The isomers have an almost planar frame structure and differ by mirror orientations of one of the rings with respect to the other rings. Vibrational spectra of the isomers are calculated in harmonic approximation at the same level of theory. The scaling factors determined experimentally for each of the two isomers have been used when comparing the calculated and experimental data. The vibrational spectra are interpreted in the whole frequency range under test. Good correlation of the experimental and calculated vibrational spectra is obtained.
\end{abstract}

Keywords: quercetin, Raman spectra, infrared absorption spectra, densityfunctional method

UDC: $535.37 ; 535.58$

\section{Introduction}

Quercetin is a plant flavonol of a flavonoid subgroup of polyphenols, which contains more than 6000 known compounds $[1,2]$. According to the literature data, quercetin is ubiquitously found in different plants (in particular, leaves) and food, in particular in vegetables and fruits, olive oil and table olives, grape and wine, onion, tea, apple, flowers, and seeds. It reveals a broad range of biological effects [3-5]. Like the other flavonoids, quercetin is active in balancing cellular reactive-oxygen level and manifests a cyto-protective function [6].

Quercetin has a broad range of therapeutic properties useful for health of humans, in particular anti-oxidant, anti-toxic, anti-cancer, anti-viral, anti-diabetic, anti-inflammation and cardiovascular effects. It is also involved in drug delivery, with therapeutic targets [7-13].

The anti-oxidant activity of quercetin, which even exceeds that of such well-known antioxidant molecules as rutin, ascorbyl and trolox, can be explained by several reasons: its ability to reduce formation of free radicals via catching them; capability to transport protons or electrons; formation of intramolecular hydrogen bonds; formation of stable radicals due to availability of hydroxyaromatic groups at each of three rings, and extensive electronic delocalization spreading over the whole quercetin molecule [14-19].

The vibrational spectra of quercetin have been earlier investigated using both Raman and IRabsorption spectroscopy methods [20-31]. However, no exhaustive interpretation of the spectra 
has been given in the above works. Nonetheless, the latter information would be very important when studying the mechanisms of binding quercetin to nucleic acids.

In the present work, we report the experimental vibrational (Raman and IR absorption) spectra of microcrystalline quercetin in the range of $400-1800 \mathrm{~cm}^{-1}$. Together, we calculate the vibrational spectra with a density-functional method for the two stable planar isomers of quercetin, and then compare the experimental data with the theory.

\section{Materials and methods}

\subsection{Quercetin}

According to nomenclature of the International Union of Pure and Applied Chemistry, quercetin is termed as 3, 3', 4', 5, 7-pentahydroxyflavanone. Its chemical formula is $\mathrm{C}_{15} \mathrm{H}_{10} \mathrm{O}_{7}$ [6]. The structure of quercetin molecule contains two aromatic rings $\mathrm{A}$ and $\mathrm{B}$ linked through a ring $\mathrm{C}$ containing oxygen, and a number of hydroxyl $\mathrm{OH}$-groups attached to the positions 3, 3', 4', 5 and 7 (see Fig. 1). The substance is poorly soluble in water.

The structural data of a quercetin crystals $\left(\mathrm{C}_{15} \mathrm{H}_{10} \mathrm{O}_{7} \cdot 2 \mathrm{H}_{2} \mathrm{O}\right.$, with the triclinic symmetry $\mathrm{P} 1$ and coordination number $z=2$ ) has been obtained with X-ray diffraction. Besides, it has been demonstrated that conformational mobility of the quercetin molecule gives rise to polymorphism of the corresponding crystals. This polymorphism can be controlled using different methods for growing single crystals (anhydrous, monohydrate and dihydrate) or co-crystals [32-37].

Quantum-mechanical studies of the structure of quercetin have been reported in Refs. [34, 38-44]. According to the studies of spatial structure of quercetin isomers [45], the quercetin molecule is either flat or almost flat for different isomers, while deviation from planarity occurs only for the ring $\mathrm{B}$, which is rotated with respect to the $\mathrm{C} 2-\mathrm{C} 1$ ' axis. We have determined optimized geometry of the two stable isomers of the quercetin molecule (referred to as is1 and is 2 further on), using the density-functional method at the CAM B3LYP/6-311++G(d,p) level. No structural restrictions have been imposed. The spatial structures of the isomers are displayed in Fig. 1.

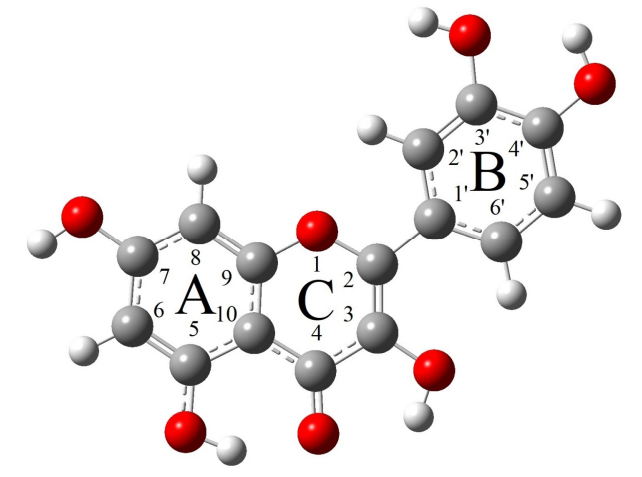

is 1

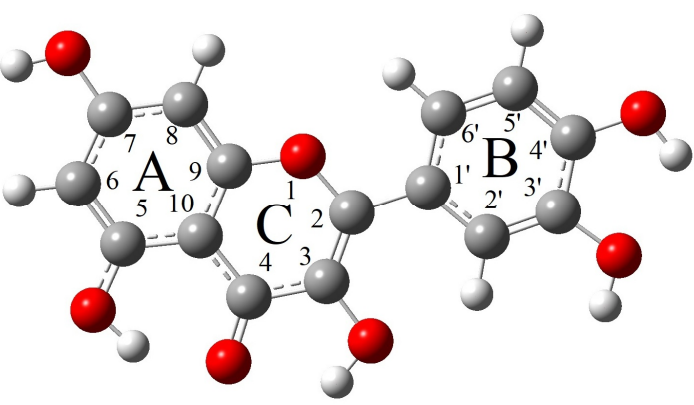

is2

Fig. 1. Optimized spatial structures of the isomers is 1 and is 2 of quercetin molecule, as calculated with densityfunctional CAM method at the level B3LYP/6-311++G(d,p). Numbers of atoms correspond to standard notation. Atoms $\mathrm{C}$ are denoted as grey circles, atoms $\mathrm{O}$ as red circles, and atoms $\mathrm{H}$ as small grey circles.

\subsection{Experiments}

The microcrystalline powder of quercetin (302 g/Mole from Borshchahivskiy CPP, Ukraine) was used in our Raman scattering and IR-absorption experiments. When preparing samples for the Raman analysis, quercetin powder was placed on a high-quality calcium fluoride plate $\left(\mathrm{CaF}_{2}\right.$ from 
Crystran Ltd, Poole, UK). This was done in order to minimize any possible spectral contributions from a sample substrate. The Raman spectra were recorded using a custom-made inverted Raman microscope equipped with a $40^{\mathrm{x}}$ objective (water immersion and numerical aperture equal to 1.0).

Since the long-wavelength absorption edge for quercetin lies in the region $\sim 500 \mathrm{~nm}[23]$, a 785-nm continuous-wave Ti:sapphire tunable laser (Coherent) was employed for exciting a sample. This provided a laser-power density of $30 \mathrm{~mW} / \mu^{2}$ at the sample. A back-scattered light from the sample was collected by an objective and filtered using two laser-blocking filters (RazorEdge $0^{\circ}$ Longpass filter, Semrock). The Raman-scattered light was focused onto an entrance slit of a monochromator (IsoPlane 320, Princeton Instruments) and set at $30 \mu \mathrm{m}$ in order to reject off-focus light and obtain high spectral resolution. The monochromator was equipped with a 600 line/mm diffraction grating.

Finally, the spectra were acquired using a back-illuminated CCD (PyLoN:400BR-eXcelon $C C D$, Princeton Instruments) cooled cryogenically at $-120^{\circ} \mathrm{C}$. To improve signal-to-noise ratio, a signal accumulation mode was used, with the exposure time amounting to $30 \mathrm{~s}$. The measurements were performed at the room temperature in the spectral range $350-2000 \mathrm{~cm}^{-1}$, with the spectral resolution not worse than $2 \mathrm{~cm}^{-1}$.

Fourier-transformed infrared absorption spectra in the mid-IR range were measured with a Thermo Scientific Nicolet iS50 spectrometer. The samples were probed in a microcrystalline phase, using a single-bounce attenuated total-reflection technique. The appropriate powders were mechanically pressed on a diamond surface. The spectra were measured in the range $375-2000 \mathrm{~cm}^{-1}$, with the maximum spectral resolution being slightly less than $1 \mathrm{~cm}^{-1}$. Built-in attenuated total reflection corrections were used to compensate for the effective path length of evanescent wave over the entire wavelength range.

In some cases, the experimental spectra were processed using Origin and PeakFit programs. This enabled correcting the data with respect to the band positions, the number of band components, etc.

\subsection{Calculations}

Optimized geometries of the stable isomers is 1 and is 2 of the quercetin molecule were calculated with the density-functional method at the CAM B3LYP/6-311++G(d,p) level. No structural restrictions were imposed in our calculation procedures (see Fig. 1). The two isomers differ by the mirror orientations of the ring B with respect to the rings A and C. At the same level of theory, their vibrational (both Raman and IR-absorption) spectra were calculated in a harmonic approximation. The density-functional calculations were performed using a Gaussian09 program package [46]. Our calculations demonstrated that the isomers of the quercetin molecule have indeed an almost planar frame structure, and deviations from the planarity are practically absent.

Since the density-functional technique usually overestimates the frequencies, the scaling factors of 0.976 (for is1) and 0.974 (for is2) were used when comparing the calculated and experimental data. This correction can easily be understood following from to the known errors present in the calculations of interatomic interactions due to a limited set of basic functions [47]. Usually the experimental and calculated Raman spectra are more similar to each other than the IR-absorption spectra. As a consequence, they were more convenient when finding the correspondence among the experimental and calculated frequencies and, therefore, determining the scaling factors. The values 0.976 (is 1 ) and 0.974 (is2) provided the best correspondence between the calculated and experimental data. The scaling factors proved to be close to unity in our case, thus indicating that the basic set used by us was sufficient for the molecule under study.

The frequencies and the relative intensities of the spectral lines with regard for the corrections mentioned above are presented in Table, along with a detailed interpretation of all of the vibrations. 


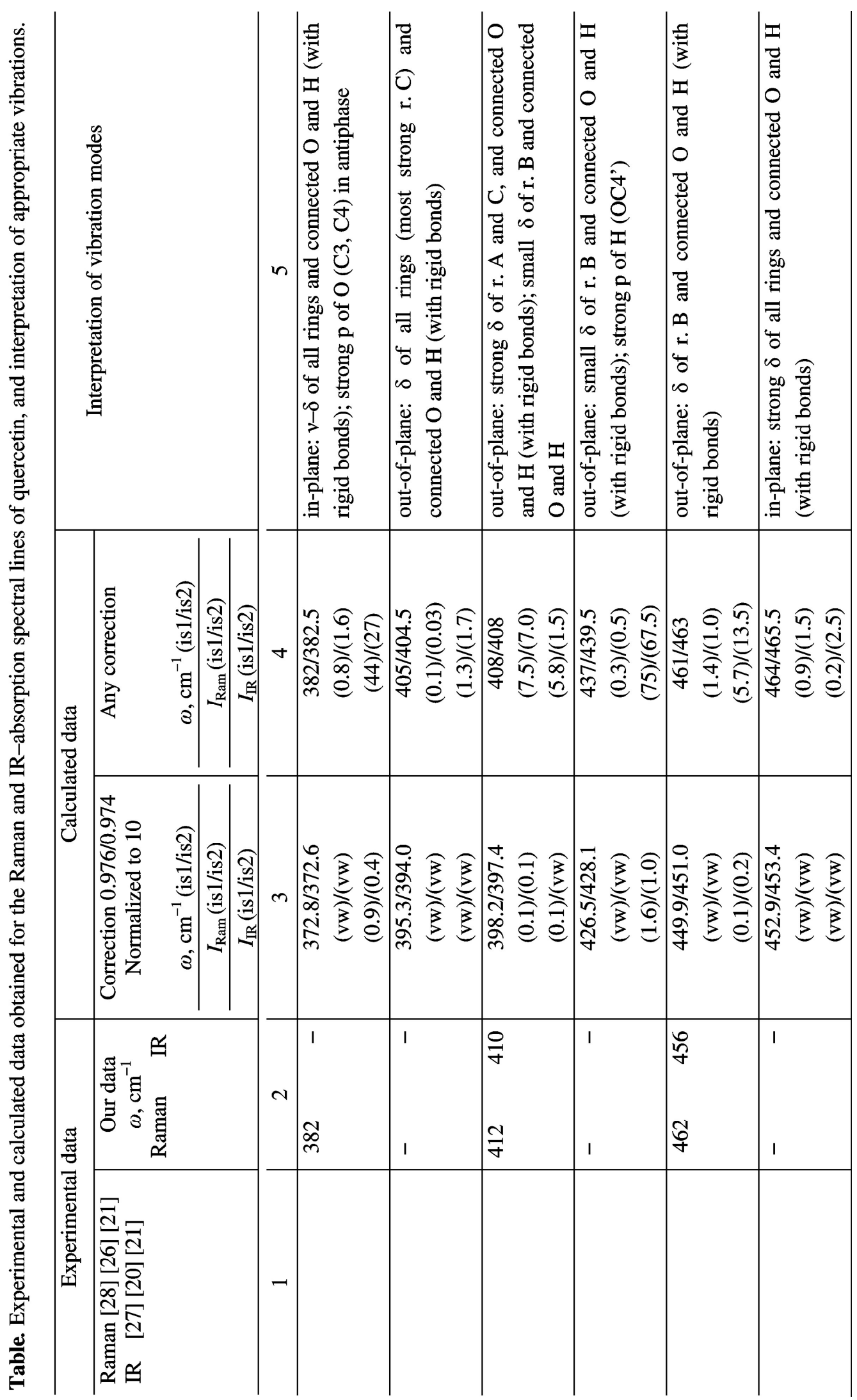




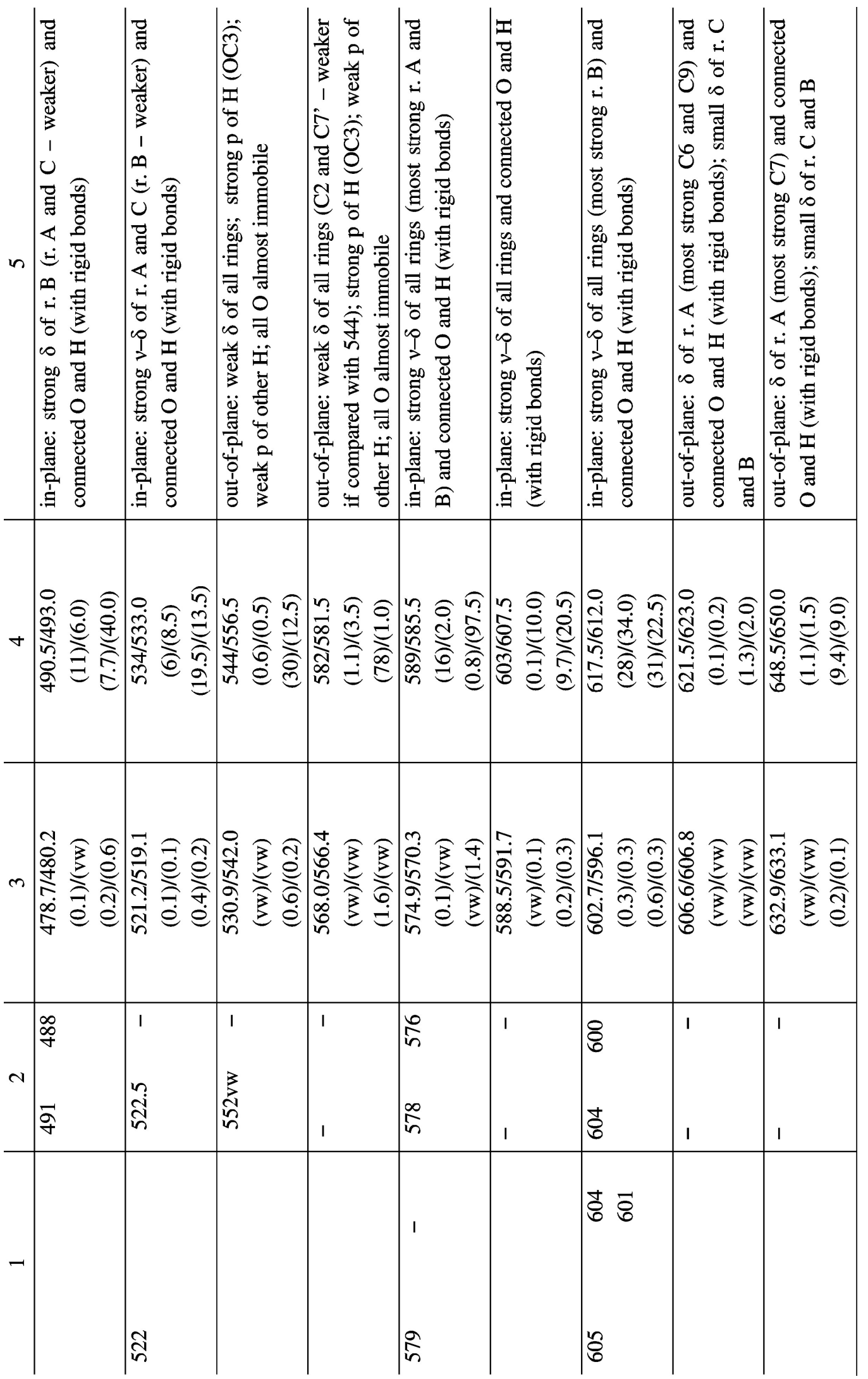

Ukr. J. Phys. Opt. 2021, Volume 22, Issue 4 


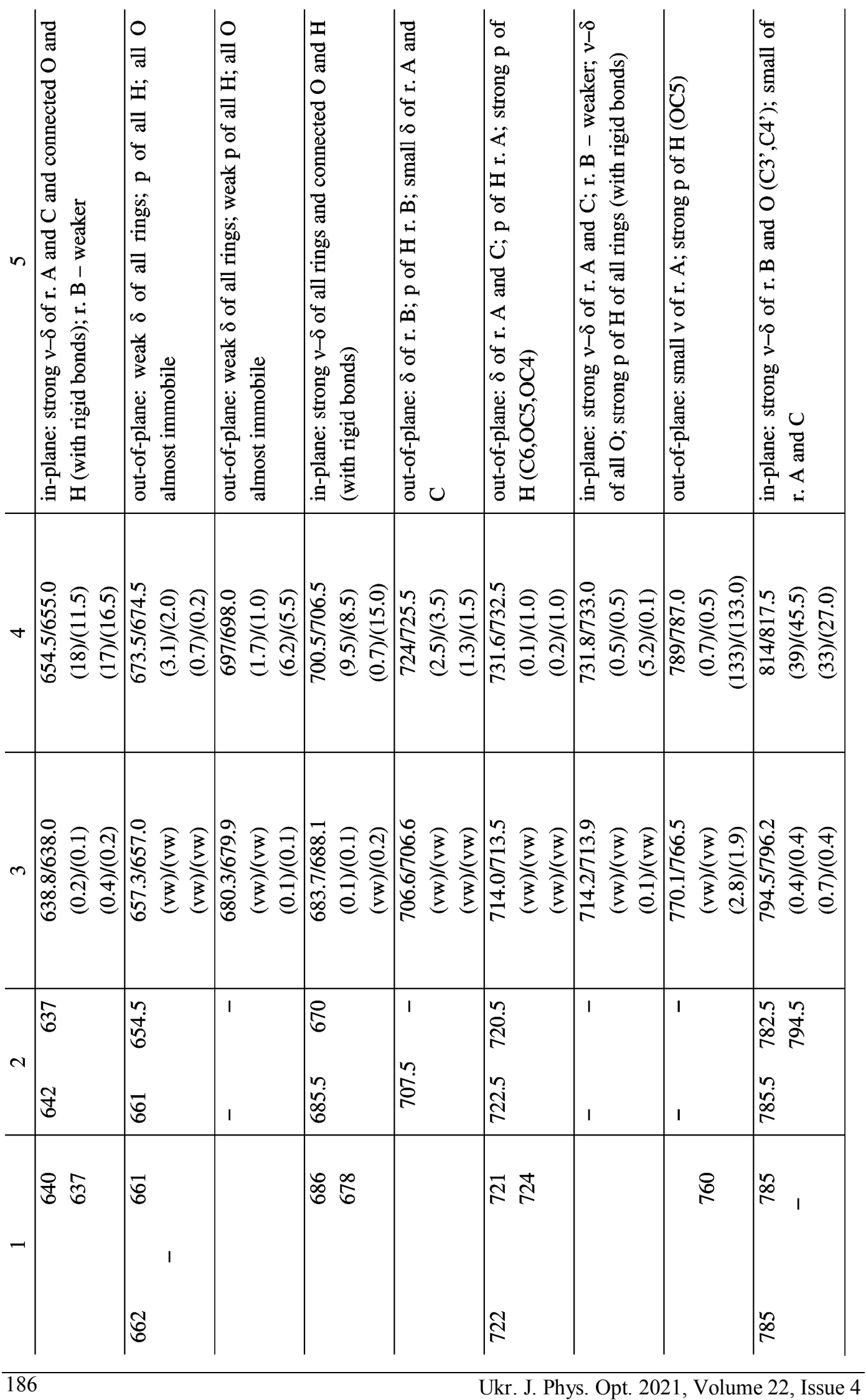




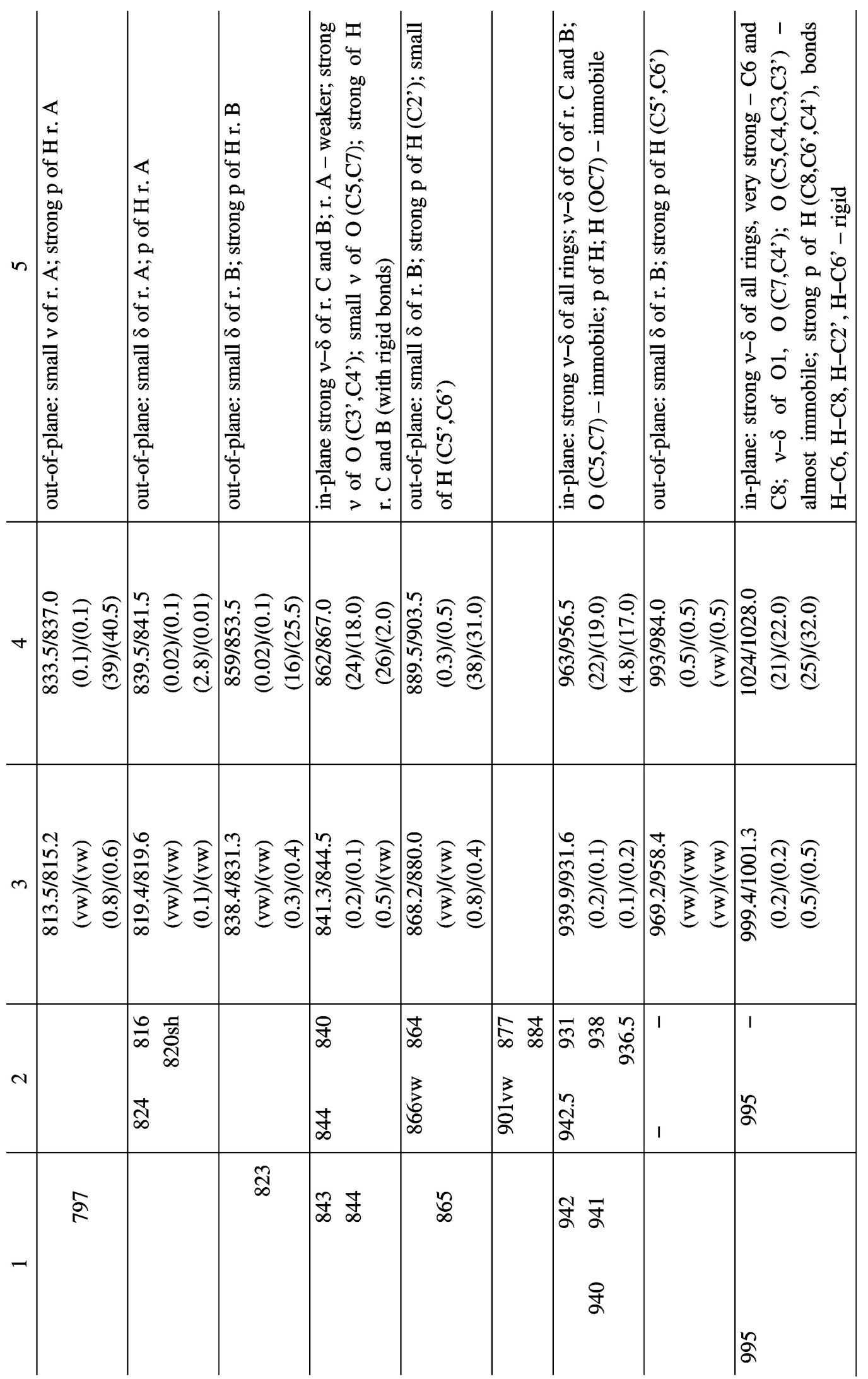

Ukr. J. Phys. Opt. 2021, Volume 22, Issue 4 


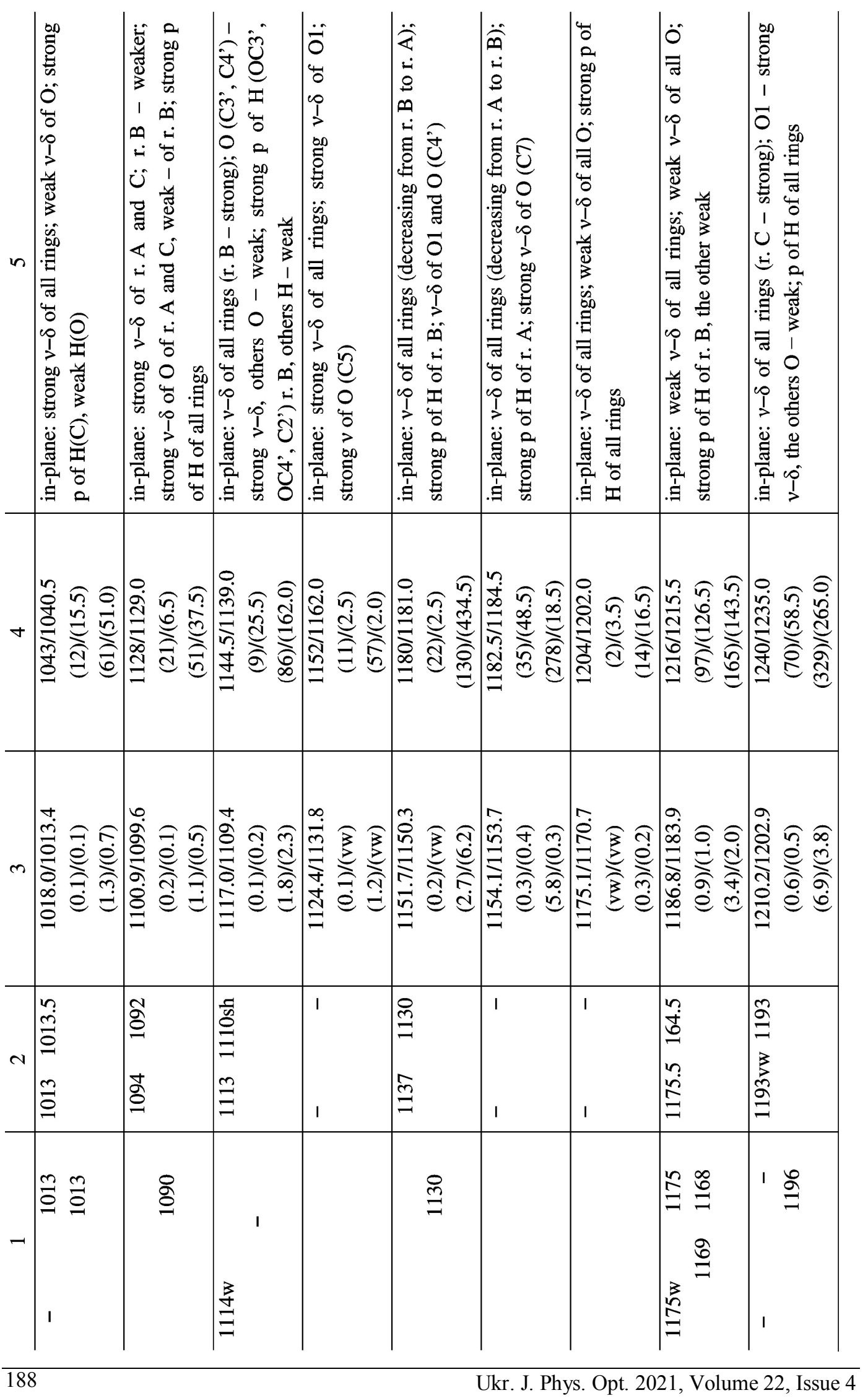




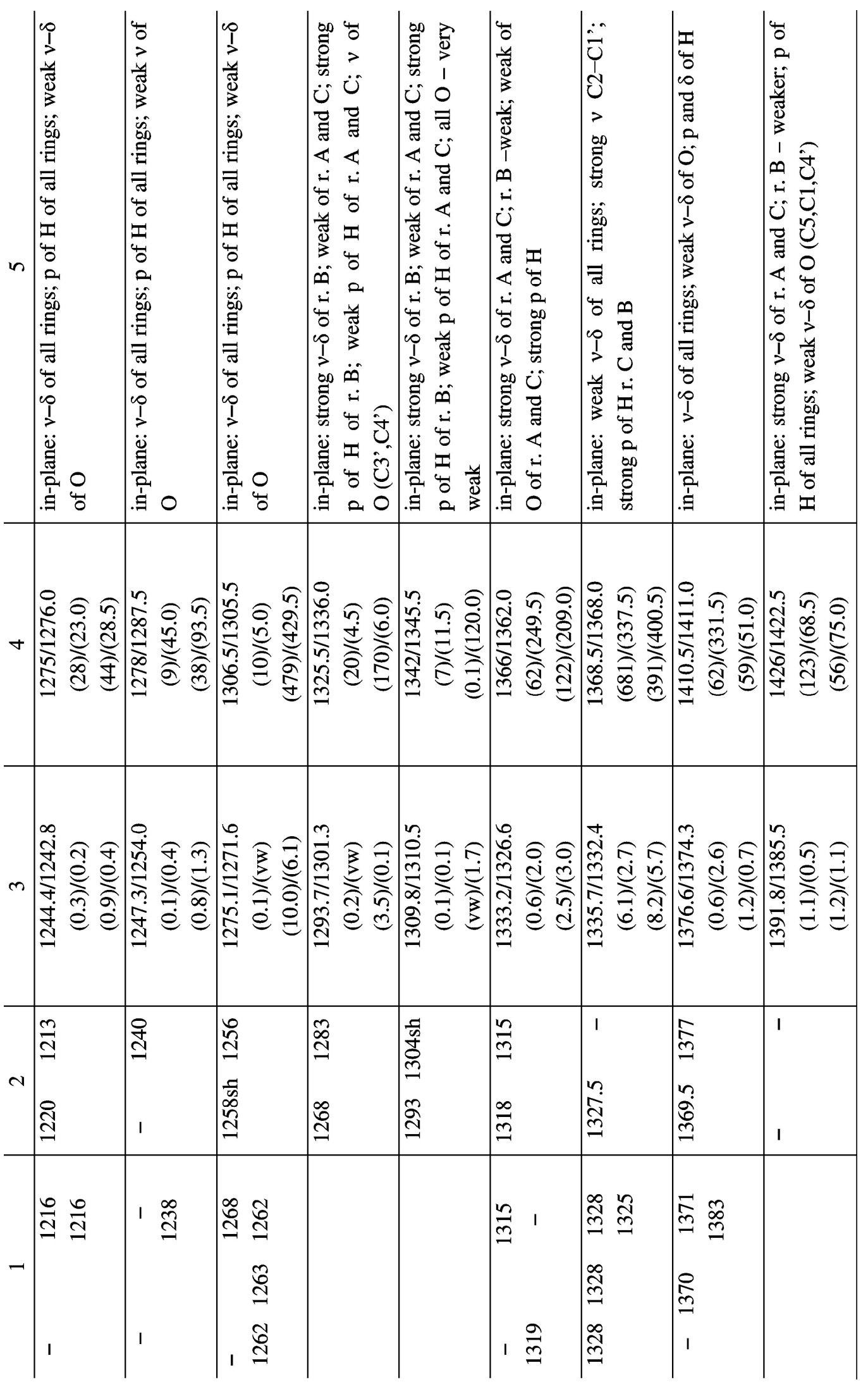

Ukr. J. Phys. Opt. 2021, Volume 22, Issue 4 


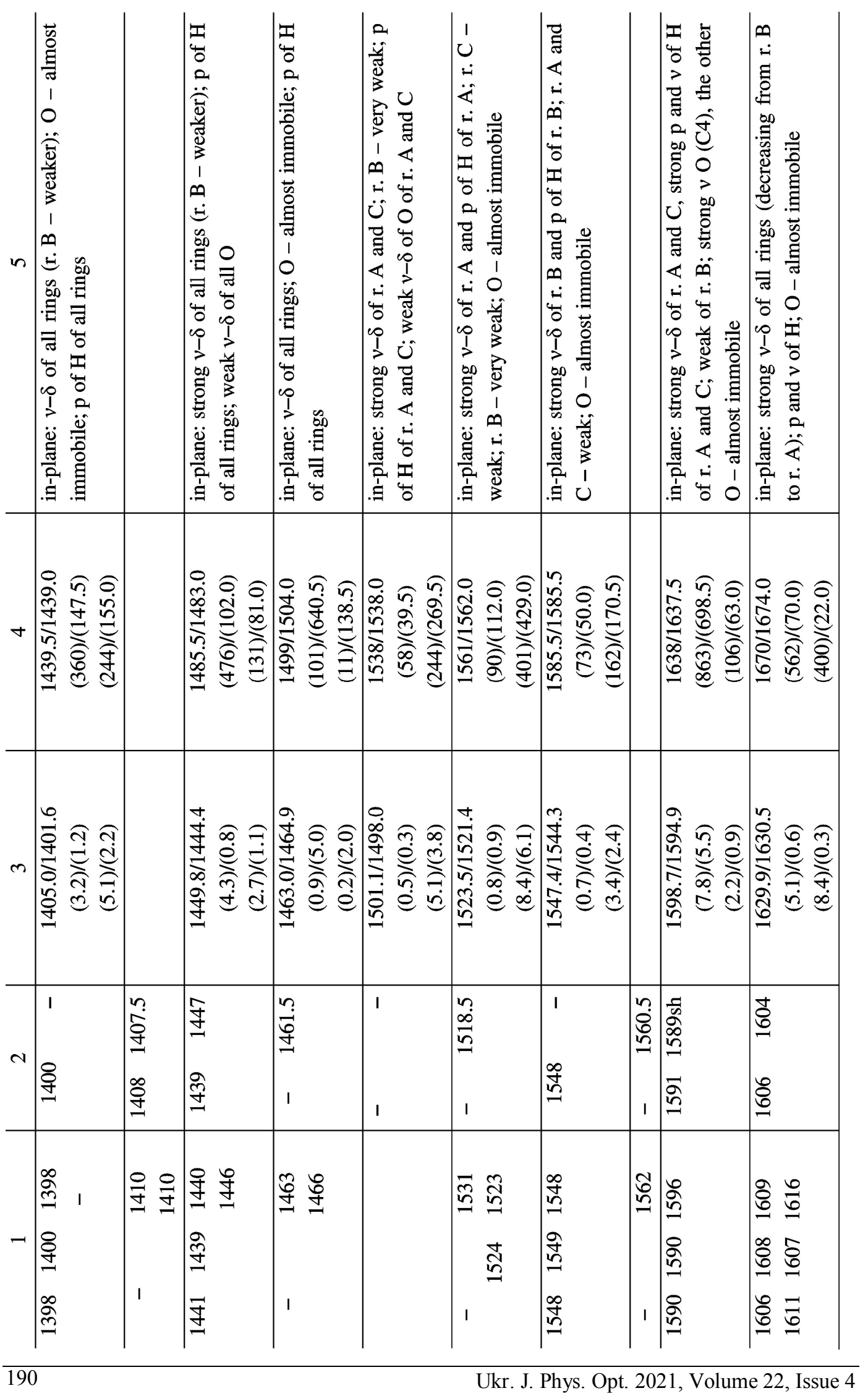




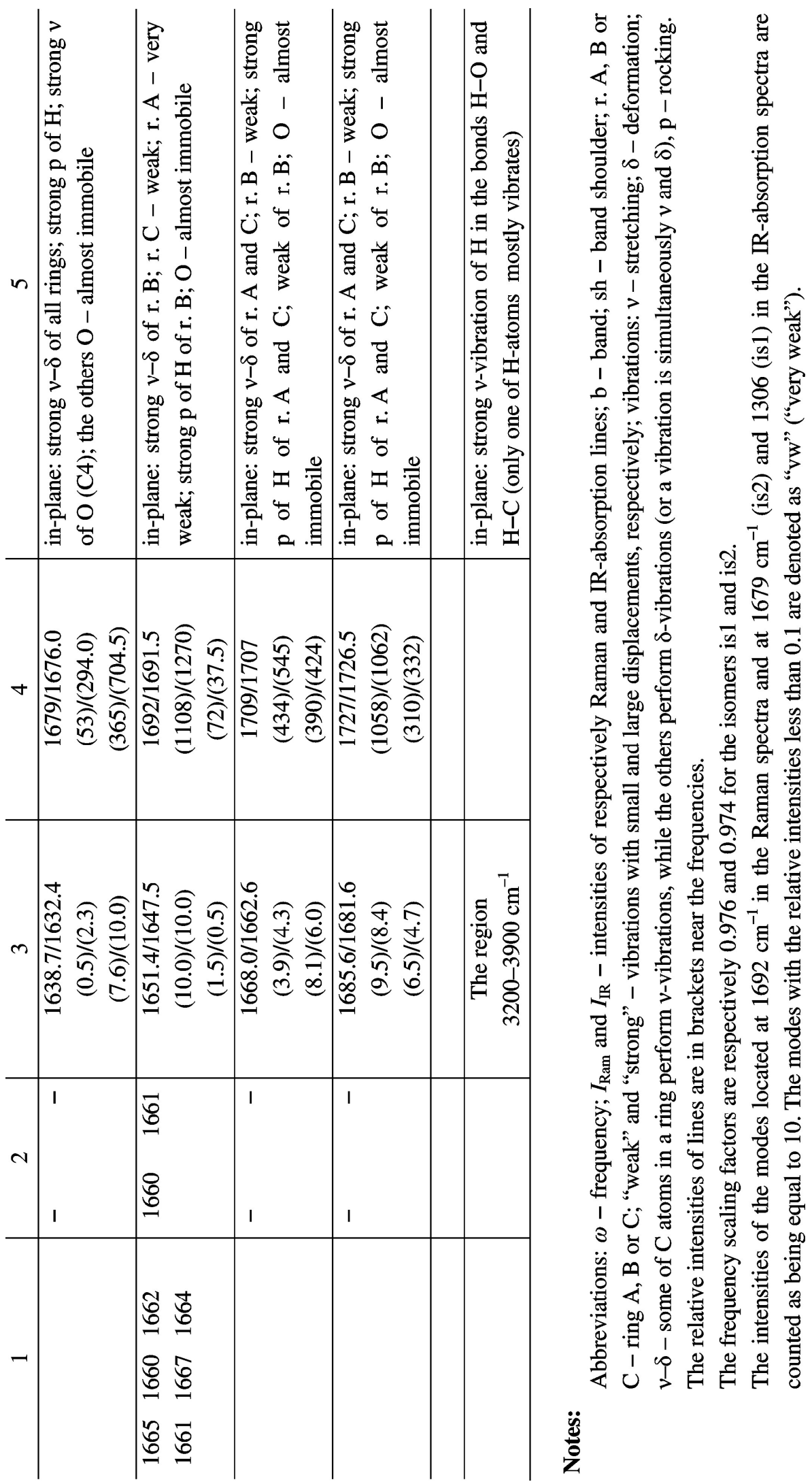

Ukr. J. Phys. Opt. 2021, Volume 22, Issue 4 


\section{Results and discussion}

As already mentioned, the quercetin crystal $\mathrm{C}_{15} \mathrm{H}_{10} \mathrm{O}_{7} \cdot 2 \mathrm{H}_{2} \mathrm{O}$ is described by a triclinic symmetry (P1 and $z=2$ ) [32-37]. Due to a low symmetry, there are no degenerate vibrations in the vibrational spectra. The correspondence between the 'crystalline' and 'molecular' modes is unambiguous. The most essential difference between the spectra typical for 'free' and crystalline quercetin had to reveal itself in the region of very low frequencies (i.e., for so-called external vibrations). In the range of intermediate and high frequencies (i.e., internal vibrations), the influence of crystal structure is very weak. A duplication of the number of vibrations (because of the fact $z=2$ ) and some shift in the vibrational bands take place. However, the splitting is insignificant so it can be neglected in any practical situation. Therefore we believe that the comparison of the experimental vibrational spectra of microcrystalline quercetin with the spectra calculated for the quercetin molecule is fairly correct in our operation range $400-1800 \mathrm{~cm}^{-1}$ (see Fig. 2 and Fig. 3). This fact has been further confirmed by a subsequent analysis.

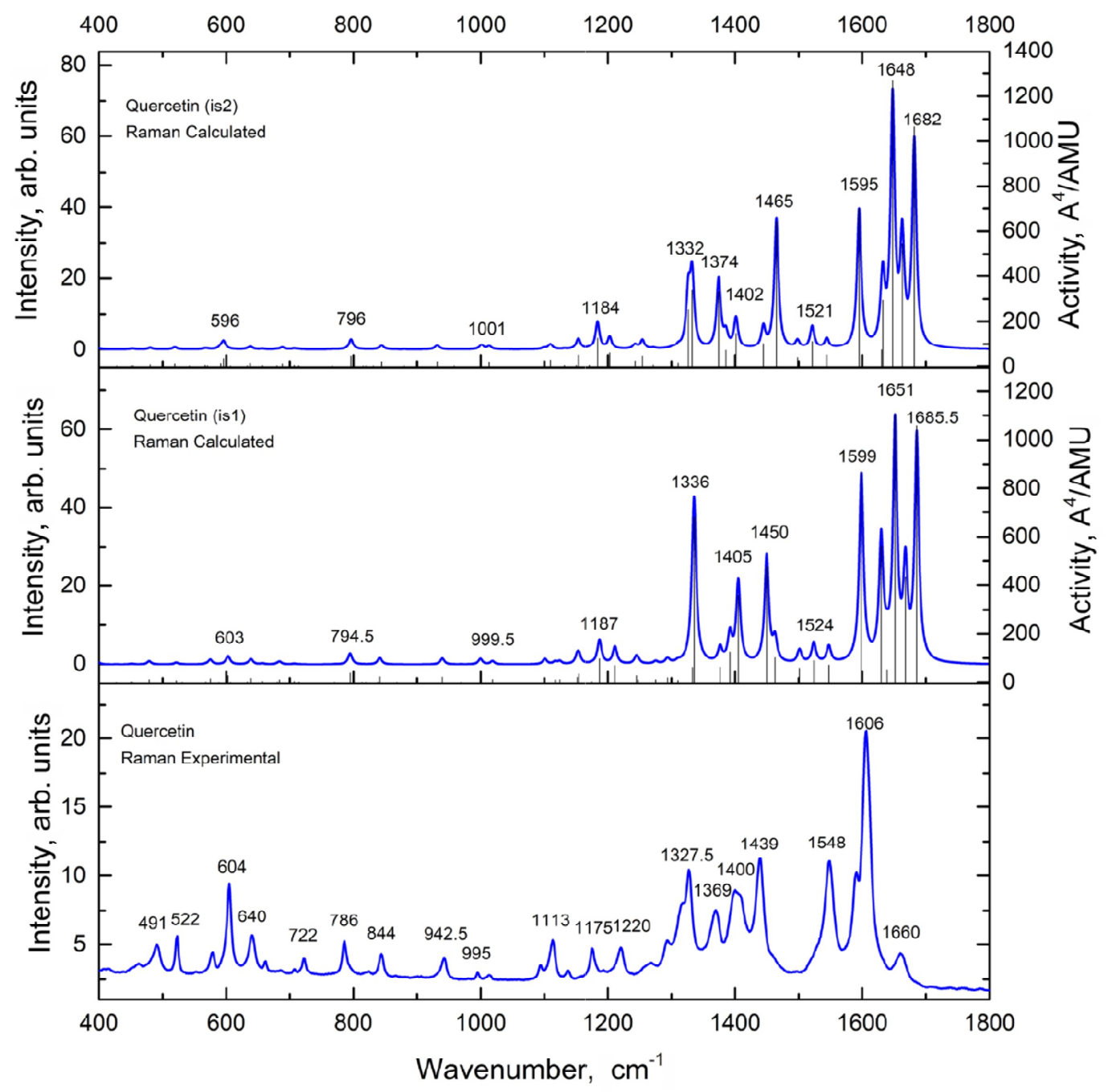

Fig. 2. Raman spectra calculated for quercetin isomers is 1 and is 2 and corrected using the scaling factors (upper panels), and experimental Raman spectrum obtained in the range $400-1800 \mathrm{~cm}^{-1}$ (lower panel). The excitation wavelength is $\lambda_{\mathrm{ex}}=785 \mathrm{~nm}$. 
The calculated spectrum for the quercetin molecule, $\mathrm{C}_{15} \mathrm{H}_{10} \mathrm{O}_{7}$, contains $90(3 \cdot 32-6)$ nondegenerate vibrations. About 60 of these vibrations lie in the region $400-1700 \mathrm{~cm}^{-1}$ and $\sim 15$ in the most relevant region $1300-1700 \mathrm{~cm}^{-1}$. The frequencies up to $400 \mathrm{~cm}^{-1}$ correspond to the outof-plane vibrations of the rings and/or attached atoms (or groups). The region $400-1000 \mathrm{~cm}^{-1}$ contains both the out-of-plane and in-plane vibrations of the rings and the attached atoms, whereas only the in-plane vibrations of the aromatic rings and the attached atoms can be found above $1000 \mathrm{~cm}^{-1}$.

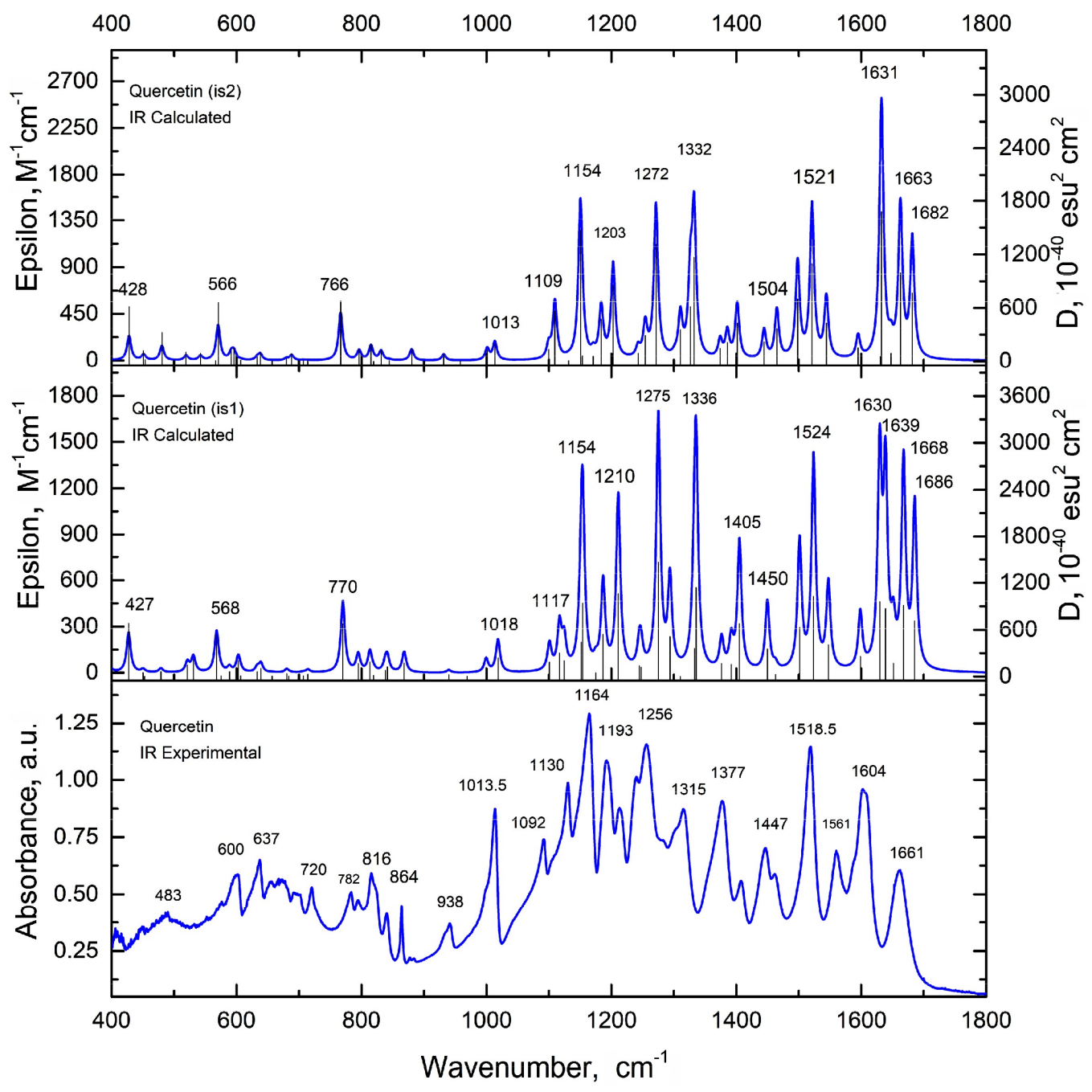

Fig. 3. IR-absorption spectra calculated for quercetin isomers is 1 and is 2 and corrected using the scaling factors (upper panels), and experimental IR-absorption spectrum obtained in the range 400-1800 $\mathrm{cm}^{-1}$ (lower panel).

The high-frequency region, $3200-3900 \mathrm{~cm}^{-1}$, contains the modes corresponding to the valence vibrations of $\mathrm{CH}$-bonds, with small displacements of the other atoms, mainly $\mathrm{C}$. Here, we are more interested in the region $1300-1700 \mathrm{~cm}^{-1}$. The in-plane vibrations of quercetin in this region are the most intense. Moreover, resonance interactions of the vibrations of quercetin and the bases of large molecules (e.g., DNA and RNA) are possible in this region. It is in this region that we have earlier observed a resonance interaction of berberine and DNA vibrations in the Raman spectra of an aqueous berberine-DNA solution $[48,49]$. 
The experimental and calculated Raman and IR-absorption spectra in the range 400-1800 $\mathrm{cm}^{-1}$ are presented in Fig. 2 and Fig. 3, respectively. A fairly good correlation between the experimental and calculated Raman spectra is observed in the whole spectral range. This concerns both the frequencies and the intensities of vibrations. The correlation between the intensities of vibrations in the IR-spectra is somewhat worse. In the region up to $1200 \mathrm{~cm}^{-1}$, the intensities of the calculated vibrations are very small (by some orders of magnitude) when compared with the experimental data. It is worthwhile that some of weak calculated modes (e.g., that located at $1547 \mathrm{~cm}^{-1}$ ) have been found to be high-intensity modes in the experimental spectra, while some modes calculated as intense ones have not been observed in the experimental spectra or they have had very low intensities (e.g., the mode located at $\sim 1650 \mathrm{~cm}^{-1}$ ). Furthermore, a few lines of an unknown nature have been revealed in the experimental spectra. For instance, this concerns the lines located at 1560 and $1407.5 \mathrm{~cm}^{-1}$ in the IR spectrum and the line at $1408 \mathrm{~cm}^{-1}$ in the Raman spectrum.

We attribute some discrepancies between the experimental and calculated spectra to the fact that the calculations are usually based upon ions or molecules, while the experiments are conducted on crystallohydrates. Since dipolarity of the vibrations in IR-absorption processes is important, a presence of dipole water molecules (or OH-groups) in the samples might have led to dipole-dipole interactions with the molecules. The results of these interactions might be revealed in the IR-absorption spectra. The appropriate influence on the Raman spectra is weaker, since the Raman scattering processes are associated with the electronic system, and the effect of dipoledipole interactions on the vibrational system is less direct.

The frequencies obtained from the experiment and the corresponding frequencies calculated using the scaling factors are presented in Table. We note that our experimental Raman spectrum appears to be quite similar to the Raman spectrum presented in the study [28]. In particular, the frequencies presented in Ref. [28] (16 modes) and Ref. [26] (8 modes) coincide very well (up to $1-2 \mathrm{~cm}^{-1}$ ) with our data. The frequencies of the IR-modes reported in Ref. [27] also agree well with our data, although only for 4 modes. For a comparison, we have included in Table some of the results obtained by the other authors [21, 26-28].

\section{Conclusion}

Summing up, in the present work we have calculated the Raman and IR-absorption spectra for the two planar isomers of the quercetin molecule, using the density-functional theory at the CAM B3LYP/6-311++G(d,p) level. The optimized geometry of the quercetin molecule has also been deduced. The results of calculations correlate fairly well with our experimental data obtained for microcrystalline quercetin in the spectral range $400-1800 \mathrm{~cm}^{-1}$. Note that this range is significant from the viewpoint of interaction of quercetin with DNA.

The interpretation of the Raman bands of quercetin suggested by us can be used when analyzing the interactions of quercetin with nuclei acids and some other biomolecules. We have also demonstrated that the density-functional method can be successfully used for this aim and manifests a satisfactory reliability. This can be utilized when calculating the vibrational spectra for the other flavonoid subgroups of polyphenols, for which it could be complicated (or even impossible for some reasons) to obtain the Raman vibrational spectra.

\section{References}

1. Davis J M, Murphy E A and Carmichael M D, 2009. Effects of the dietary flavonoid quercetin upon performance and health. Curr. Sports Med. Rep. 8: 206-213. 
2. Trouillas P, Marsal P, Siri D, Lazzaroni R and Duroux J-L, 2006. A DFT study of the reactivity of $\mathrm{OH}$ groups in quercetin and taxifolin antioxidants: the specificity of the 3-OH site. Food Chem. 97: 679-688.

3. Bentz A B, 2009. A review of quercetin: chemistry, antioxidant properties, and bioavailability. J. Young Investig. 19.

4. Cadenas E and Packer L. Handbook of Antioxidants. New York: Marcel Dekker, 2002.

5. David A V A, Arulmoli R and Parasuraman S, 2016. Overviews of biological importance of quercetin: a bioactive flavonoid. Pharmacogn. Rev. 10: 84-89.

6. Drugbank. https://www.drugbank.ca/drugs/DB04216.

7. Abarikwu S O, Pant A B and Farombi E O, 2012. Dietary antioxidant, quercetin, protects sertoli-germ cell coculture from atrazine-induced oxidative damage. J. Biochem. Mol. Toxicol. 26: 477-485.

8. Aguirre L, Arias N, Macarulla M T, Gracia A and Portillo M P, 2011. Beneficial effects of quercetin on obesity and diabetes. Open Nutraceuticals J. 4: 189-198.

9. Nathiya S, Durga M and Devasena T, 2014. Quercetin, encapsulated quercetin and its application - a review. Int. J. Pharm. \& Pharm. Sci. 10: 20-26.

10. Pham-Huy L A, He H and Pham-Huy C, 2008. Free radicals, antioxidants in disease and health. Int. J. Biomed. Sci. 4: 89-96.

11. Porcu E P, Cossu M, Rassu G, Giunchedi P, Cerri G, Pourová J, Najmanová I, Migkos T, Pilařová V, Nováková L, Mladěnka $\mathrm{P}$ and Gavini $\mathrm{E}, 2018$. Aqueous injection of quercetin: an approach for confirmation of its direct in vivo cardiovascular effects. Int. J. Pharm. 541: 224-233.

12. Ramadan M F and Asker M M S, 2009. Antimicrobical and antivirial impact of novel quercetinen riched lecithin. J. Food Biochem. 33: 557-571.

13. Rauf A, Imran M, Khan I A, ur-Rehman M, Gilani S A, Mehmood Z and Mubarak M S, 2018. Anticancer potential of quercetin: a comprehensive review. Phytother. Res. 32: 2109-2130.

14. Cai X, Fang Z, Dou J, Yu A and Zhai G, 2013. Bioavailability of quercetin: problems and promises. Curr. Med. Chem. 20: 2572-2582.

15. Gao S, Sofic E and Prior R L, 1997. Antioxidant and pro-oxidant behavior of flavonoids: structure-activity relationships. Free Radic. Biol. Med. 22: 749-760.

16. Jovanovic S V, Steenken S, Hara Y and Simic M G, 1996. Reduction potentials of flavonoid and model phenoxyl radicals. Which ring in flavonoids is responsible for antioxidant activity. J. Chem. Soc. Trans. 2: 2497-2504.

17. Van Acker S A B E, de Groot M J, van den Ber D-J, Tromp M N J L, Donné-Op den Kelder G, van der Vijgh W J F and Bast A, 1986. A quantum chemical explanation of the antioxidant activity of flavonoids. Chem. Res. Toxicol. 9: 1305-1312.

18. Van Acker S A B E, van der Berg D J, Tromp M N J L, Griffen D H, van Bennekom W P, van der Vijgh W J F and Bast A, 1996. Structural aspects of antioxidant activity of flavonoids. Free Radical Biol. Med. 20: 331-342.

19. Van Acker S A, de Groot M J, van den Berg D J, Tromp M N, Donné-Op den van Acker S A B E, Bast A and van der Vijgh W J F, 1998. The structural aspects in relation to antioxidant activity of flavonoids. Antioxid. Health Dis., pp. 221-251.

20. Karmakar A and Singh B, 2019. Spectroscopic analysis and theoretical investigation of hydrogen bonding interaction of quercetin with different acceptor molecules. J. Mol. Struct. 1180: 698-707.

21. Cornard J P, Merlin J C, Boudet A C and Vrielynck L, 1997. Structural study of quercetin by vibrational and electronic spectroscopies combined with semiempirical calculations. Biospectrosc. 3: 183-193. 
22. Jurasekova Z, Garcia-Ramos J V, Domingo C and Sanchez-Cortes S, 2006. Surface-enhanced Raman scattering of flavonoids. J. Raman Spectrosc. 37: 1239-1241.

23. Jurasekova Z, Domingo C, Garcia-Ramos J V and Sanchez-Cortes S, 2014. Effect of pH on the chemical modification of quercetin and structurally related flavonoids characterized by optical (UV-visible and Raman) spectroscopy. Phys. Chem. \& Chem. Phys. 16: 12802-12811.

24. Dimitrić Marković J M, Marković Z S, Milenković D and Jeremić S, 2011. Application of comparative vibrational spectroscopic and mechanistic studies in analysis of fisetin structure. Spectrochim. Acta. A. 83: 120-129.

25. Numata $Y$ and Tanaka H, 2011. Quantitative analysis of quercetin using Raman spectroscopy. Food Chem. 126: 751-755.

26. Borghetti G S, Carini J P, Honorato S B, Ayala A P, Moreira J C F and Bassani V L, 2012. Physicochemical properties and thermal stability of quercetin hydrates in the solid state. Thermochim. Acta. 539: 109-114.

27. Raza A, Xu X, Xia L, Xia C, Tang J and Ouyang Z, 2016. Quercetin-iron complex: synthesis, characterization, antioxidant, DNA binding, DNA cleavage, and antibacterial activity studies. J. Fluoresc. 26: 2023-2031.

28. Pompeu D R, Larondelle Y, Rogez H, Abbas O, Fernández Pierna J A and Baeten V, 2018. Characterization and discrimination of phenolic compounds using Fourier transform Raman spectroscopy and chemometric tools. Biotechnol. Agron. Soc. Environ. 22: 13-28.

29. Hanuza J, Godlewska P, Kucharska E, Ptak M, Kopacz M, Mączka M, Hermanowicz K and Macalik L, 2017. Molecular structure and vibrational spectra of quercetin and quercetin-5'sulfonic acid. Vibr. Spectr. 88: 94-105.

30. Teslova T, Corredor C, Livingstone R, Spataru T, Birke R L, Lombardi J R, Canamares M V and Leona M, 2007. Raman and surface-enhanced Raman spectra of flavone and several hydroxyl derivatives. J. Raman Spectrosc. 38: 802-818.

31. Kanakis C D, Tarantilis P A, Polissiou M G, Diamantoglou S and Tajmir-Riahi H A, 2005. DNA interaction with naturally occurring antioxidant flavonoids quercetin, kaempferol, and delphinidin. J. Biomolec. Struct. Dynam. 22: 719-724.

32. Rossi M, Rickles L F and Halpin W A, 1986. The crystal and molecular structure of quercetin: A biologically active and naturally occurring flavonoid. Bioorg. Chem. 14: 55-69.

33. Jin G Z, Yamagata Y and Tomita K I, 1990. Structure of quercetin dihydrate. Acta Cryst. C. 46: 310-313.

34. Domagała S, Munshi P, Ahmed M, Guillot B and Jelsch C, 2010. Structural analysis and multipole modelling of quercetin monohydrate - a quantitative and comparative study. Acta Cryst. B. 67: 63-78.

35. Filip X, Grosu I-G, Miclăuş M and Filip C, 2013. NMR crystallography methods to probe complex hydrogen bonding networks: application to structure elucidation of anhydrous quercetin. Cryst. Eng. Comm. 15: 4131-4142.

36. Filip X and Filip C, 2015. Can the conformation of flexible hydroxyl groups be constrained by simple NMR crystallography approaches? The case of the quercetin solid forms. Solid State Nucl. Magn. Res. 65: 21-28.

37. Kavuru P, Aboarayes D, Arora K K, Clarke H D, Kennedy A, Marshall L, Ong T T, Perman J, Pujari T, Wojtas $Ł$ Łukasz and Zaworotko M J, 2010. Hierarchy of supramolecular synthons: persistent hydrogen bonds between carboxylates and weakly acidic hydroxyl moieties in cocrystals of zwitterions. Cryst. Growth Des. 10: 3568-3584.

38. Aparicio S A, 2010. Systematic computational study on flavonoids. Int. J. Mol. Sci. 11: 2017-2038. 
39. Leopoldini M, Marino T, Russo N and Toscano M, 2004. Density functional computations of the energetic and spectroscopic parameters of quercetin and its radicals in the gas phase and in solvent. Theor. Chem. Acc. 111: 210-216.

40. Antonczak S, 2008. Electronic description of four flavonoids revisited by DFT method. J. Mol. Struct.: THEOCHEM. 856: 38-45.

41. Bogdan T V, Trygubenko S A, Pylypchuck L B, Potyahaylo A L, Samijlenko S P and Hovorun D M, 2001. Conformational analysis of the quercetin molecule. Sci. Notes of NaUKMA. 19: 456-460.

42. Bogdan T V, Trygubenko S A, Pylypchuck L B and Hovorun D M, 2003. Acid-base properties of quercetin molecule: results of quantum-chemical calculations. Repts. Natl. Acad. Sci. Ukraine. 4: 151-154.

43. Kelder G, van der Vijgh W J and Bast A, 1996. A quantum chemical explanation of the antioxidant activity of flavonoids. Chem. Res. Toxicol. 9: 1305-1312.

44. Cornard J P, Dangleterre L and Lapouge C, 2005. Computational and spectroscopic characterization of the molecular and electronic structure of the $\mathrm{Pb}(\mathrm{II})$-quercetin complex. J. Phys. Chem. A. 109: 10044-10051.

45. Brovarets' O O and Hovorun D M, 2020. Conformational diversity of the quercetin molecule: a quantum-chemical view. J. Biomol. Struct. Dyn. 38: 2817-2836.

46. Frisch M J, Trucks G W, Schlegel H B, Scuseria et al. Gaussian 09 (Revision A.02). Gaussian, Inc., Wallingford CT (2009).

47. Halls M D, Velkovski J and Schlegel H B, 2001. Harmonic frequency scaling factors for Hartree-Fock, S-VWN, B-LYP, B3-LYP, B3-PW91 and MP2 with the Sadlej pVTZ electric property basis set. Theor. Chem. Acc. 105: 413-421.

48. Kutovyy S Yu, Pashchenko V G and Zaika L A, 2005. Manifestation in the Raman spectra of the effect of berberine on DNA. Visn. Kyiv Univ., Ser. Fiz.-Mat. 7: 12-16.

49. Yashchuk V M, Kutovyy S Yu, Bashmakova N V, Pashchenko V G, Dudko O V and Zaika L A, 2007. The manifestation in Raman and photoluminescence spectra of the DNA-berberine interactions. Nauk. Zapys. Kyiv-Mogyla Acad., Ser. Fiz.-Mat. 51: 42-48.

Kutovyy S., Savchuk R., Bashmakova N., Stanovyi O. and Palchykivska L. 2021. Vibrational spectra of quercetin and their interpretation with quantum-mechanical density-functional method. Ukr.J.Phys.Opt. 22: 181 - 197. doi: 10.3116/16091833/22/4/181/2021

Анотація. Для мікрокристалічного порошку квериетину одержсано експериментальні коливні спектри (комбінаиійне розсіяння та ІЧ-поглинання) в спектральному діапазоні 400-1800 см ${ }^{-1}$ за кімнатної температури. Оптимізовані геометрії двох стабільних ізомерів молекули квериетину обчислено за методом функиіоналу щільності на рівні CAM B3LYP/6-311++G(d,p). Вищезазначені ізомери мають майже площинну структуру каркасу і відрізняються дзеркальною орієнтаиією одного з кілець щодо інших. На иьому ж рівні теорії в гармонічному наближенні обчислено коливні спектри ізомерів. Коефіцієнти маситабування, визначені експериментально для кожного 3 двох ізомерів, було використано в порівнянні розрахункових та експериментальних даних. Коливні спектри проінтерпретовано для всього дослідженого діапазону частот. Одержано високу кореляцію між експериментальними та розрахунковими коливними спектрами. 